\title{
Battlefield First Aid: a simple, systematic approach for every soldier
}

Lt Col TJ Hodgetts

MB BS(Hons), FRCP, FFAEM, DipIMC RCSEd, Dip MedEd, RAMC

Consultant and Specialty Adviser in Accident and Emergency Medicine

MDHU Frimley Park Hospital, Camberley, Surrey GU16 $5 U J$.

e-mail:tim.hodgetts@virgin.net

Maj CG Hanlan

AGC(ETS)

Training Development Advisor

\section{Maj (Ret'd) CG Newey}

RAMC

Technical Author,

MOD-AMD Keogh Barracks, Ash Vale, Aldershot, Hants GU12 5RR

SUMMARY: First aid training for the trained soldier has been modified to incorporate the best available current clinical evidence and clinical experience. This annual training requirement will be achieved in one day and is introduced as Individual Training Directive (Army) 3 (ITD(A) 3) on 1 April 1999. With the exception of a short introductory video, the course is entirely taught and assessed on practical models. ITD(A) 3 teaches a systematic approach to every incident and to each injured soldier. This is presented in a robust, waterproof pocket aide memoire of Battlefield First Aid Drills, which is an individual issue item. The soldier must start with the MASTER DRILL to control the incident, and will then follow the INJURED SOLDIER DRILL to identify and treat life-threatening injuries. The best available clinical experience has resulted in the replacement of the three-sided dressing with the Asherman Chest Seal for open pneumothorax, and the introduction of a simple physiology based triage system. The best available clinical evidence has led to the removal of basic life support in the context of a soldier with no vital signs on the battlefield. It is retained as an 'add on' package for peace and peace-keeping environments.

\section{Introduction}

On 1 April 1999 first aid training for the trained soldier, part of Army Training Directive 5 (ATD 5), Medical Training in units), is replaced by ITD(A) 3, Battlefield First Aid). This is more than a cosmetic change of name. Best clinical experience has been combined with the best available evidence to provide all soldiers with life-saving skills. A simple, systematic approach is taught for the management of any incident involving casualties, and then for each injured soldier.

ITD(A) 3 is based on a pocket-sized aide memoire of Battlefield First Aid Drills, to be issued to every soldier (Table 1). The aide memoire has pre-determined decisions for scene

Table 1

Contents of the aide memoire

\begin{tabular}{|l|l|}
\hline Start here & Master Drill \\
\hline Drill 1 & The injured soldier \\
\hline Drill 2 & The unresponsive soldier \\
\hline Drill 3 & Difficulty breathing \\
\hline Drill 4 & Bleeding \\
\hline Drill 5 & Breaks and dislocations \\
\hline Drill 6 & Burns \\
\hline Drill 7 & Pain relief \\
\hline Drill 8 & Multiple casualties \\
\hline Drill 9 & Hot and cold control \\
\hline Drill 10 & Evacuation rules \\
\hline Information & Equipment location \\
\hline
\end{tabular}


Table 2

ITD $(A) 3$ course programme

\begin{tabular}{|c|c|}
\hline $0800-0810$ & Introduction \\
\hline 0810-0830 & Casualty demonstration 1 \\
\hline 0835-0935 & Practical skills $(2 \times 30 \mathrm{~min})$ \\
\hline 0940-1010 & Skills demonstration \\
\hline $1010-1030$ & COFFEE \\
\hline $1030-1200$ & Practical skills $(3 \times 30 \mathrm{~min})$ \\
\hline $1200-1220$ & Casualty demonstration 2 \\
\hline $1220-1300$ & LUNCH \\
\hline $1300-1430$ & Casualty scenario practice \\
\hline $1435-1635$ & TESTING \\
\hline $1640-1710$ & Battleshock \\
\hline $1710-1730$ & Results and debrief \\
\hline
\end{tabular}

now proven to be of no value. However, protocols based on evidence alone will often not be flexible enough to manage every clinical situation. Such protocols must be tempered by the best available clinical experience. ITD(A) 3 incorporates best available evidence with best available clinical experience.

\section{Teaching strategy}

ITD(A) 3 is taught and tested entirely on practical models, with the exception of the 10 minute introduction (Table 2). A casualty management demonstration is given immediately following the introduction. This can be with a simulated live casualty, or a training manikin (Laerdal Resusci Anne, Dräger Trauma Max). The aim of the demonstration is to show each soldier, "This is what you can achieve by the end of this day." An identical demonstration is repeated before the casualty management practice, which provides an opportunity to consolidate the systematic approach to the scene and the casualty.

Every soldier must have the opportunity to practice each skill, making small group teaching essential. There is one instructor for a maximum of 8 students. There is a prescriptive lesson plan for each practical skill to ensure consistency within courses where more than one instructor is teaching, and between courses. On each skill station there is emphasis on the systematic approach to the incident, then concentration on the drill relevant to the skill being taught. There is a problem-based approach to treating the injured soldier, for example "the unresponsive soldier", "difficulty breathing" and "bleeding". Individual skills are taught within the context of the determined sequence of decisions and actions for each problem.

ITD(A) 3 is designed to be taught and tested outdoors. This adds validity to the training. The option remains for the training to be performed indoors subject to local preference.

\section{Assessment strategy}

It is possible to assess various levels of learning. Knowledge is assessed by the recall of facts, and understanding by the recall of principles. Practical ability is assessed by observed performance of a psychomotor skill. Combining knowledge, understanding and practical ability within a simulated situation assesses synthesis. Judgement is assessed through the ability to reach the correct decision.

But what we require is practical soldiers, who perform first aid as a drill irrespective of the situation. There is no written assessment. To recall a medical list or algorithm is not required and for this reason there is no Multiple Choice Paper, which
Table 3

Assessment structure

\begin{tabular}{|l|l|}
\hline Part A & $\begin{array}{l}\text { 1.State the aim of Battlefield First Aid } \\
\text { 2.Place the instructor in the 3/4 prone } \\
\text { position } \\
\text { 3. Open the airway using the jaw thrust } \\
\text { (Resusci Anne) } \\
\text { 4. Follow the Bleeding drill to treat a } \\
\text { wound on a limb. The candidate must } \\
\text { show an effective field dressing, } \\
\text { elevation and direct pressure (using } \\
\text { Resusci Anne, a simulated casualty, or } \\
\text { Trauma Max) }\end{array}$ \\
\hline Part B & $\begin{array}{l}\text { Follow the aide memoire to treat a single } \\
\text { casualty (Resusci Anne, simulated } \\
\text { casualty, or Trauma Max) with two } \\
\text { injuries from a prescribed list. }\end{array}$ \\
\hline
\end{tabular}

characteristically tests knowledge. Similarly, the reasons for doing first aid actions are less important to the soldier than the ability to perform them effectively - so there is no Short Answer Paper, which characteristically tests understanding. The focus therefore is on testing individual practical skills, and the synthesis of these skills within a simulated casualty situation.

The test is in two parts (Table 3 ). The soldier is required to pass both parts. A failure in either or both parts requires the soldier to re-attend the $\operatorname{ITD}(\mathrm{A}) 3$ training day. Decision-making is not formally tested, as the management decisions are pre-determined within the aide memoire.

Assessment conditions mirror the teaching conditions for the individual skills, and for the casualty management scenario. For consistency, each casualty will have two injuries from a list published in the Battlefield First Aid Trainer's Instructional Handbook. This avoids the scenario being made more difficult for the strong candidate or easier for the weak candidate. Additionally, a checklist is followed of key testing objectives. The same checklist is used by the soldiers to assess their peers in the practice session, thereby informing the soldiers of the exact criteria by which they will be assessed.

\section{What's been added?}

A simple, systematic approach to every incident involving causalties has been added. This is the "Master Drill" (Fig 1), and is the first page of the aide memoire. The soldier has been given a template to follow, irrespective of the nature of the incident (vehicle accident, casualties from gunfire, casualties from blast). The principle of an "all hazard" approach to multiple casualty incidents is in parallel to the approach to civilian disasters $(1,2)$.

The ability to triage, or to prioritise casualties for treatment, is fundamental to the effective management of an incident with more than one casualty. Priorities for evacuation must also be assessed, and may be altered by initial treatment. If a system is to be used by every soldier it must be simple, safe, rapid and reproducible. Such a system is the "Triage Sieve" $(2,3)$. This is a physiological system that can be performed in under one minute. No understanding is required, merely the ability to follow the simple algorithm (Fig 2). ITD(A) 3 utilises the latest refinements to this system. referred to as the "Modified Triage Sieve" (4).

There is little a soldier can do for difficulty breathing. One thing is to recognise chemical contamination and administer appropriate antidotes according to the NBC Tasks. The other thing is to recognise and treat a sucking chest wound. Traditional teaching has been to use the three-sided waterproof dressing, which in theory will act as a flutter valve. At best, this can be 


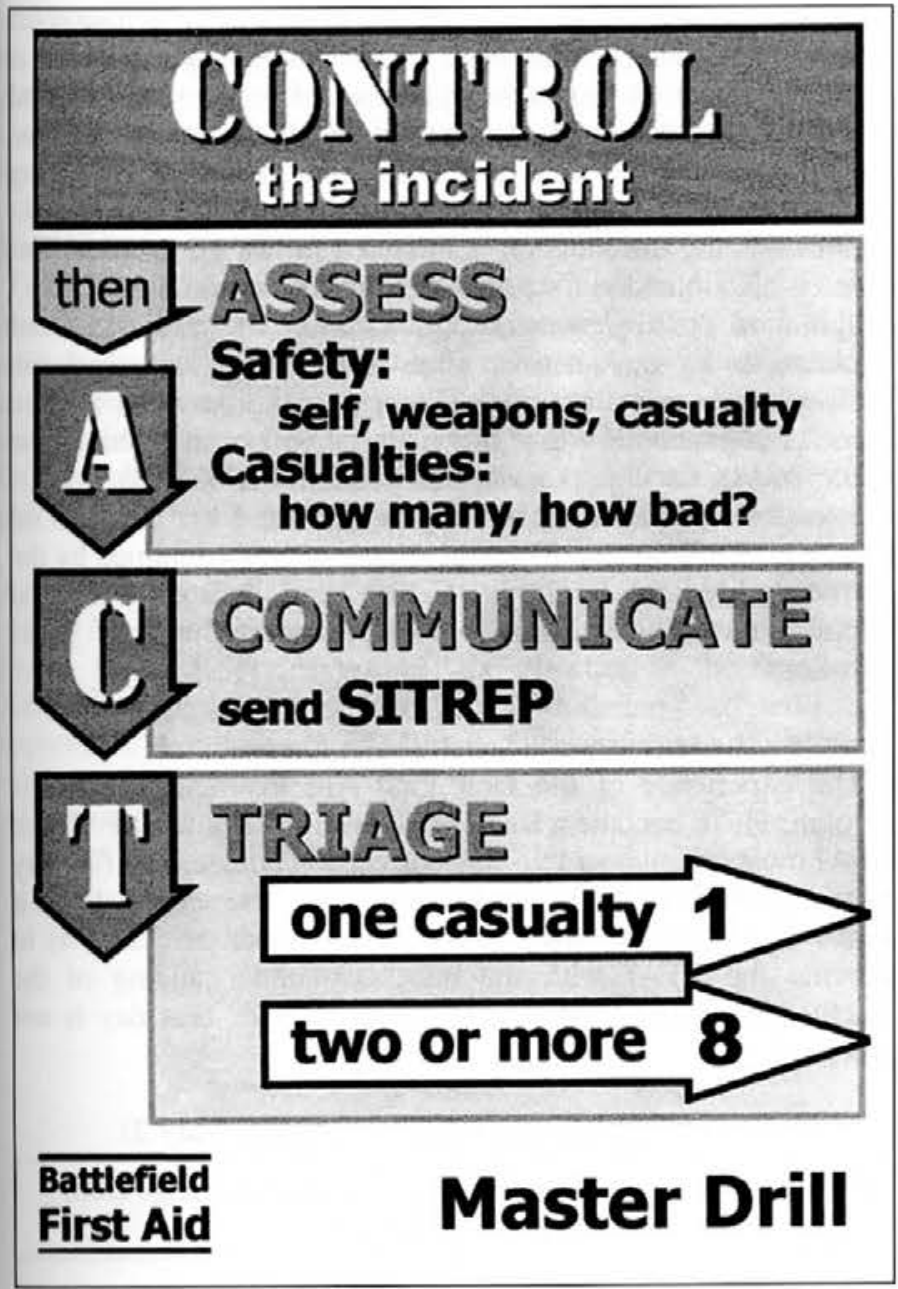

Fig 1. The Master Drill

expected to be inconsistent. In reality, a soldier may not have the adhesive tape to construct the device and will be frustrated in his attempts to produce a functioning device that can save a life. A highly adhesive disc, with central rubberised flutter valve has replaced the three-sided dressing - this is the "Asherman Chest Seal". It is effective in seconds, and will be consistent between operators.

The tourniquet has been a controversial tool in first aid. It is included in the "Bleeding" drill as a last resort, for severe limb bleeding that remains uncontrolled following dressing, pressure, elevation, a second dressing and as firm pressure as the casualty can tolerate. The argument that a tourniquet should be released after a period of time is not an issue here. A tourniquet will only be applied to save life from severe blood loss uncontrolled by any other means. It is to remain in place until reassessed at a higher level of care. ' $T$ ' is to be written on the forehead, together with the time in 24-hour clock. The casualty will be evacuated as Priority 1.

This evacuation decision is one of a series of predetermined evacuation priorities listed in the final drill, "Evacuation Rules".

\section{What's been removed?}

The most noticeable skill that has been removed is basic life support (cardiopulmonary resuscitation, CPR). This is a bold step, but it follows sound clinical evidence.

Civilian evidence reveals that the survival from cardiac arrest following blunt or penetrating trauma where there are no vital signs pre-hospital is $0 \%(5)$. In this meta-analysis of 23 published studies involving 2294 patients arriving at hospital with no signs of life following trauma, there were also no intact neurological survivors in those $2 \%$ of blunt trauma victims who lost vital signs in the ambulance and who were successfully resuscitated following an emergency room thoracotomy.

There is a slim chance of survival from cardiac arrest following penetrating trauma if vital signs are lost within five minutes of reaching hospital where a thoracotomy is performed on arrival (5).

Civilian experience also shows that the survival from cardiac arrest as a result of primary cardiac disease (coronary artery thrombosis) is directly proportional to the time to defibrillation (6-8).

When this is extrapolated to the battlefield it can be seen that there is nothing to be gained from starting basic life support in a soldier who has no vital signs following blunt trauma (fall, vehicle accident, crush). Equally, movement of a casualty with cardiac arrest following penetrating trauma to an advanced medical facility that can perform a thoracotomy is unrealistic within 5 minutes of losing the vital signs. Should a soldier suffer an ischaemic cardiac arrest on the battlefield there will be no readily available defibrillator. It is appropriate to regard these soldiers as dead. To encourage basic life support in such circumstances will falsely raise the hopes of the first aider, may place the rescuers at unnecessary risk when attempting to transport the body rapidly to the next line of care, and will divert resources from treating those who are salvageable. All that is achieved is a change in the geographical site of death.

This is the reasoning behind not teaching CPR as part of ITD(A) 3. The value of being able to provide CPR in peace, peacekeeping and peace-enforcing environments is recognised. In these circumstances, the Battlefield First Aid Trainer is

\section{Drill 8 - Multiple Casualties}

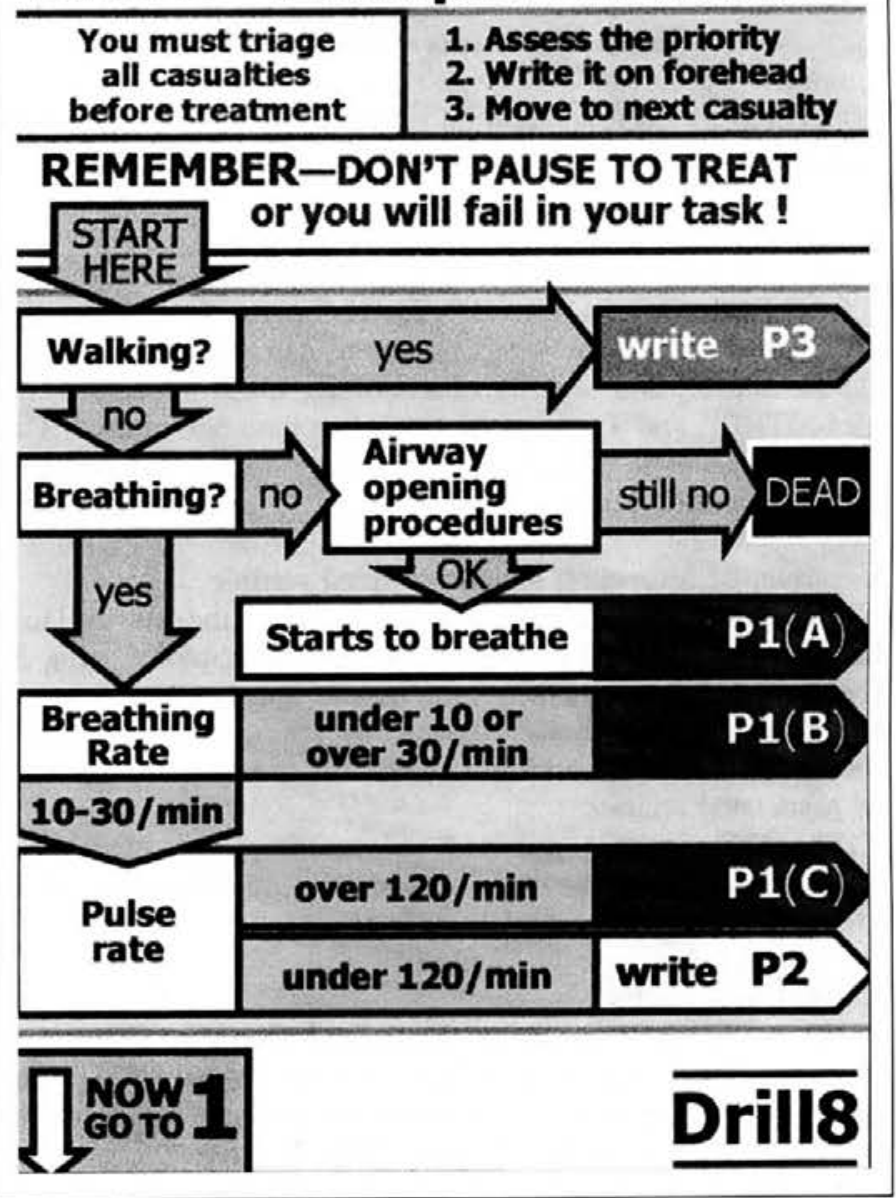

Fig 2. The Modified Triage Sieve 


\section{Drill 1 - Injured Soldier}

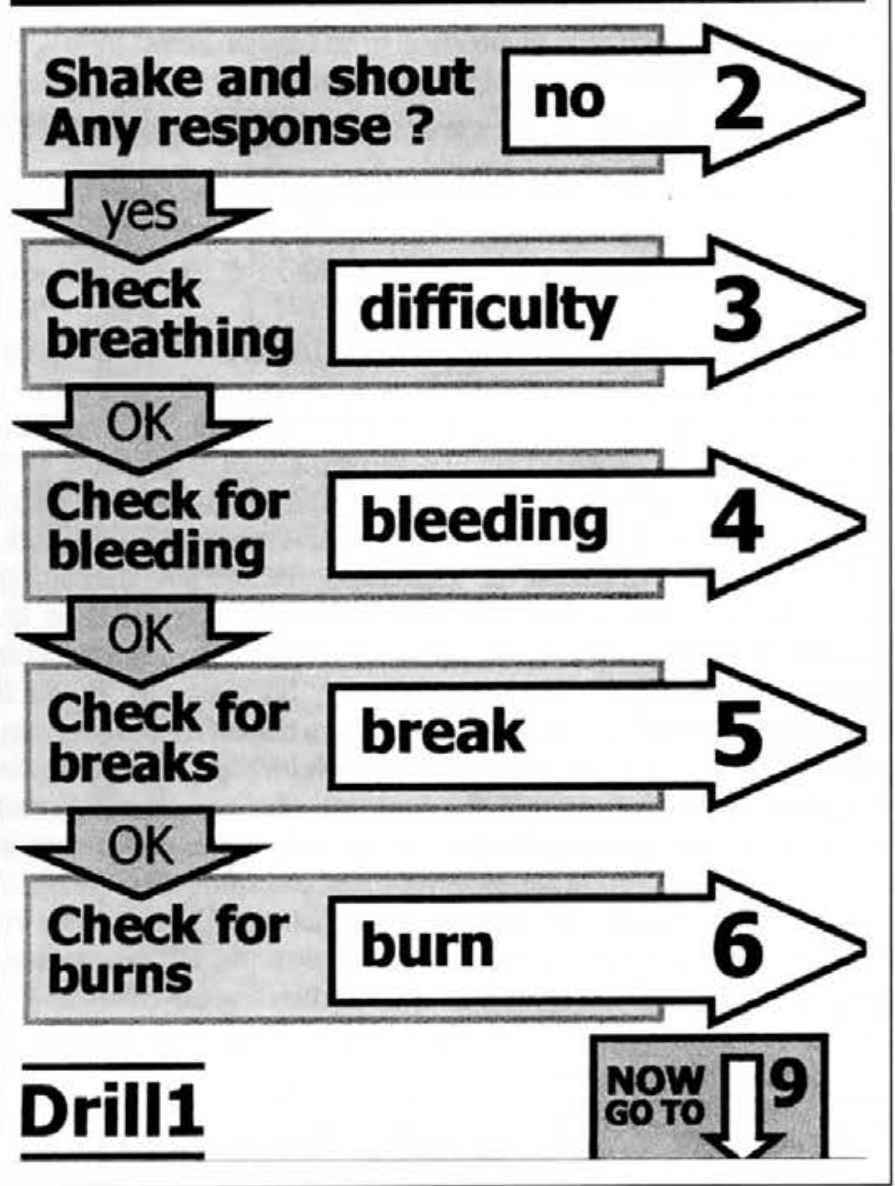

Fig 3. The Injured Soldier Drill

encouraged to teach an "add on package" of basic life support, outside the ITD(A) 3 programme.

\section{A systematic approach to every incident}

The systematic approach to every incident is remembered as "CONTROL then ACT". CONTROL the incident, Assess for safety (personal safety, weapons safety, safety of the casualty) and the number and severity of casualties, Communicate with a brief SITREP, and Triage if there is more than one injured. This is the "Master Drill" (Fig 1) which is the common start point for every incident involving casualties.

\section{A systematic approach to each injured soldier}

After completing Syntax, having completed the Master Drill, the rescuer is referred to Drill 1, the "Injured Soldier" (Fig 3). The rescuer is posed a series of simple questions, which will direct management along Airway, Breathing and Circulation lines. The rescuer will consider every drill, to prompt a search for the associated injuries.

The soldier is not required to remember the algorithms, although this may be encouraged in environments where reference to the pocket book is difficult.

\section{Instructional materials}

ITD(A) 3 is centred on the Battlefield First Aid Drills Aide Memoire. This is a personal issue item, pocket-sized (shirt pocket that is, not wedged into a battledress pocket), produced on waterproof pages, with a robust binding. Space is given to personalise the book, and to write notes opposite each drill. The last page is completed by the individual as a reminder to where additional equipment items (first field dressings, Asherman chest seals) are carried at section level. Care has been taken that text is visible in a dark environment when viewed with a red torch, and that those who are red-green colour blind can discern the colours.

The introduction is delivered as a verbal presentation utilising 10 laminated flip charts, or by showing the introductory video. In either case, the introduction is intended to last 10 minutes. The video is also intended for refresher training outside the ITD(A) 3 programme. A supplementary video clip of the indications and applications for an Asherman Chest Seal is included, which can be used to support the practical teaching station when a video recorder is available. All of this material will be available in the 1998 'Aid to Save' package (catalogue number 056/98).

Intended developments to support $\operatorname{ITD}(\mathrm{A}) 3$ are a CD-ROM trainer, and a Web-site. The Web-site is to be maintained by the Defence Medical Training Centre and will provide the opportunity for instructors to view model answers to novel questions.

\section{Training the trainers}

The experience of the Unit First Aid Instructor (UFAI) is recognised. To become a Battlefield First Aid Trainer (BFAT) the UFAI must complete a two-day conversion course. The first day of this is the ITD(A) 3, which is assessed. The second day is a series of lectures, demonstrations and workshops (Table 4) to provide the UFAI with the necessary understanding of the teaching techniques used on the BFA course. This day is not assessed.

Table 4

UFAI Conversion Course - content (day 2)

\begin{tabular}{|l|l|}
\hline Lecture & $\begin{array}{l}\text { Introduction: the need to change from } \\
\text { ATD 5 to ITD(A)3 }\end{array}$ \\
\hline Workshop & Frequently asked questions \\
\hline Workshop & $\begin{array}{l}\text { Instructional materials 1: the Aide } \\
\text { Memoire }\end{array}$ \\
\hline Lecture & Teaching a practical skill \\
\hline Demonstration & Teaching a practical skill \\
\hline Practical & Skills teaching practice \\
\hline Workshop & Instructional Materials 2: supporting \\
\hline Lecture & Assessment on ITD(A) 3 \\
\hline Demonstration & Assessment techniques \\
\hline Practical & Assessment practice \\
\hline
\end{tabular}

New instructors will attend a 5-day BFA Trainers' course at the Defence Medical Services Training Centre, which has replaced the 5-day UFAI course. As a minimum requirement potential instructors must have attended the Basic Instructional Techniques (BIT) course. The first day of the BFAT course is a "gold standard" ITD(A) 3, where the potential instructors have the opportunity to experience the course taught to the highest standard. The next $21 / 2$ days teaches the potential instructors best practice with respect to delivery of the ITD(A) 3 course. The final $11 / 2$ days is instruction on how to teach basic life support (CPR), and Health and Safety Executive accreditation. Importantly, successful completion of the BFAT course qualifies the soldier as a Battlefield First Aid Trainer, but not as an HSE First Aid Instructor.

BFA Trainers are issued with an instructional handbook. This contains instructional specifications, and a hard copy of supporting materials (flipcharts). The instructional handbook will : test pPact ç্⿳亠口冋si statio $\stackrel{10}{2}$ Conc व्राTL annus sक्ञ़ंdie cours:trồni Dosills åy ir œ Afkn $\exists$ TTL (A) A tivis 
vill act as a reference for the aide memoire, expanding on the ext of the aide memoire. There are lesson plans for each of the ractical stations, with a rigid structure that will ensure onsistency of delivery. Checklists for the teaching and testing tations are included.

\section{Conclusion}

ITD(A) 3 has replaced the first aid element of ATD 5 as the innual teaching and testing programme in first aid for trained oldiers. The opportunity has been taken to provide a practical ourse, based on the best available evidence and experience. The raining revolves around an aide memoire of Battlefield First Aid Jills, which lead the rescuer through a systematic approach to ny incident, and a systematic approach to each injured soldier.

\section{dcknowledgement}

ITD(A) 3 has been created by the Training Development Team Army Medical Services), under the direction of the Specialty Adviser in Accident and Emergency Medicine, and with the pproval of the Professor of Military Surgery.

\section{REFERENCES}

1. The Home Office. Dealing with Disaster. London: HMSO 1992:

2. Advanced Life Support Group. Major Incident Medical Management and Support: the practical approach. London: BMJ Publishing 1995:

3. Hodgetts T, Miles S. Major incidents. In: Skinner D, DRISCOLL P. EARLAM R. ABC of Major Trauma (2e). London: BMJ Publishing, 1996:

4. Hodgetts T. Triage. Pre-hospital Immediate Care 1997; 1: 110-111.

5. Boyd M, VAneK V, Bourguet C. Emergency Room Resuscitative Thoracotomy: When Is it Indicated? J Trauma 1992; 33: 714-721.

6. Stults K, Brown D, Schug V, Bean J. Prehospital defibrillation performed by emergency medical technicians in rural communities. $N$ Engl J Med 1984; 310: 219-223.

7. Cobbe S, Redmond M, Watson J, Hollingworth J, CARRINGTON D. "Heartstart Scotland" - initial experience of a national scheme for out of hospital defibrillation. BMJ 1991; 302: $1517-1520$.

8. Pionkowski R, Thompson B, Gruchow H, Aprahamian C, DARIN J. Resuscitation time in ventricular fibrillation - a prognostic indicator. Ann Emerg Med 1983; 12: 733-738. 